\title{
EFECTOS DEL MALATHION SOBRE LA ESPERMATOGÉNESIS DE RATONES MACHOS JÓVENES DE LA CEPA BALB-C53.
}

\author{
Walter Félix De la Cruz Ramírez, Karina Mabel Luján Mavila, Ubaldo Efraín Miranda Soberón ${ }^{1}$
}

\section{RESUMEN}

El presente trabajo tiene como objetivo demostrar los efectos tóxicos de una sola dosis del pesticida órganofosforado Malathion sobre la espermatogénesis de ratones jóvenes. Para ello 50 ratones machos jóvenes de 30 días de edad de la cepa Balb-C53 fueron repartidos aleatoriamente en dos grupos: uno experimental (E), que recibió 1/3 de la DL50 del Malathion comercial (Extrathion) diluido en aceite de maíz por vía intraperitoneal, y otro Control (C) que recibió sólo aceite de maíz por la misma vía. Los ratones tratados y sus controles fueron sacrificados en grupos de 5 a los: $4,8,18$, 28 y 40 días después de una sola aplicación del Malathion, y luego se midió el conteo y la morfología espermática. Después de la inyección del Malathion se observó disminución del conteo espermático a los 28 y 40 días postexposición (E: 458,00 y 519,80 millones esp. $/ \mathrm{ml}$ vs C: 683,60 y 796,40millones esp. $/ \mathrm{ml}$ respectivamente, para un p£0,05) y aumento de la teratozoospermía a los 4 y 8 días postexposición ( $E: 13,60$ y $8,40 \%$ de esp. anormales vs C: 4,60 y 2,40\% de esp. anormales respectivamente, para un $\mathrm{p} £ 0,05)$. En conclusión, la administración de una sola dosis de Malathion por vía intraperitoneal, puede afectar la espermatogénesis de los ratones machos jóvenes.

Palabras Clave: Infertilidad, Espermatogénesis, Órganofosforado, Malathion.

\section{ABSTRACT}

The Present work aims at establishing the toxic effects on spermatogenesis of a single injection of the pesticide Malathion in young mice. For it, 50 young male Balb-C53 mice of 30 days of age was distributed aleatorily in two groups: Experimental (E) that received 1/3 de la LD50 of the commercial Malathion (Extrathion) diluted in corn oil injected intraperitoneally, and another Control (C) that only received corn oil for the same road. Treated mice and their controls were sacrificed in groups of 5 at: 4, 8, 18, 28 and 40 days after injection of the Malathion, for then to measure the count and morphology spermatic. After the injection of the Malathion was observed decrease of the spermatic count at 28 and 40 days postinjection (E: 458,00 and 519,80 millons esp./ml vs C: 683,60 y 796,40 millons esp./ml respectively, p£0,05) and increase of the teratozoospermia at 4 and 8 days postinjection (E: 13,60 y $8,40 \%$ de esp. abnormal vs $C: 4,60$ y $2,40 \%$ de esp. abnormal respectively, $\mathrm{p} £ 0,05)$. In conclusion the administration of a single dose of Malathion intraperitoneally it can affect the spermatogenesis of the young male mice.

Key Words: Infertility, Spermatogenesis, Organophosphorous, Malathion.

\section{INTRODUCCIÓN}

Estudios preliminares, indican que los órganofosforados podrían tener efectos gonadotóxicos sobre el testículo y en virtud a ello producirían un descenso en la calidad del semen de ciertos animales y del hombre. Esto debido principalmente a su acción deletérea sobre la espermatogénesis $^{1-9}$

La espermatogénesis es un proceso de desarrollo y maduración, continúo y largo, de las células germinales dentro de los túbulos seminíferos. En el ratón adulto este proceso, tiene una duración de 34 a 35 días $^{3,4}$.

Como se sabe, el efecto tóxico principal de los agropesticidas órganofosforados consiste en bloquear irreversiblemente la enzima acetilcolinesterasa en varios tejidos, lo que genera síntomas de hiperactividad parasim- pático ${ }^{10}$.

Además de este efecto tóxico agudo, los órganofosforados tienen también propiedades genotóxicas y citotóxicas, gracias a que son agentes alquilantes con capacidad para alterar el normal ensamblaje de las proteínas y el ADN celular ${ }^{10-13}$. Este efecto sería el causante del descenso de la cuenta de espermatozoides y la alta teratozoospermia de los animales (ratones) expuestos a Parathion o Malathion ${ }^{3-9}$.

Motivados por estos antecedentes, y el gran uso de los órganofosforados en la zona de estudio, se planificó y realizó el presente trabajo experimental en ratones, con el objetivo de determinar los efectos gonadotóxicos del Malathion sobre la espermatogénesis de ratones jóvenes.

\section{MATERIAL Y MÉTODOS}

Sujetos de Experimentación: En el estudio se utilizaron 50 ratones machos jóvenes, de 30 días de edad y de 30 a 40 gramos de peso de la Cepa Balb-C53. Estos fueron alojados en un ambiente a una temperatura promedio de 18 a $20^{\circ} \mathrm{C}$, alimentados con pelotillas comerciales y agua a voluntad; guardando un foto período de 12 horas de luz y 12 de oscuridad.

Agente Químico: Como agente agropesticida órganosfosforado, se uso Malathion comercial (Extrathion 57\% E.C de FARMAGRO S.A.), a una concentración de $623 \mathrm{~g} / \mathrm{L}$ de Malathion, $26 \mathrm{~g} / \mathrm{L}$ de compuestos relacionados, $330 \mathrm{~g} / \mathrm{L}$ de solventes y $85 \mathrm{~g} / \mathrm{L}$ de emulsificantes.

Diseño Estudio: La DL50 del Malathion comercial para administración intraperitoneal fue determinada por el

${ }^{1}$ Facultad de Medicina Humana, Universidad Nacional "San Luis Gonzaga" Camino a Huacachina S/N, Ciudad de Ica. 
método de Reed-Muench usando 5 dosis diferentes para cada grupo de 7 animales cada uno. La DL50 hallada fue $793,8 \mathrm{mg} / \mathrm{kg}$ de peso corporal.

Posteriormente se realizó un estudio a doble ciego, de dos grupos aleatorios, con observaciones después de la aplicación del tratamiento. En este experimento, Malathion comercial $(623 \mathrm{mg} / \mathrm{ml})$ fue diluido en aceite de maíz, e inyectado intraperitonealmente a los ratones del grupo experimental $(E)$, usando una sola dosis equivalente al $1 / 3$ de la DL50. Los controles (C) fueron inyectados con el mismo volumen de aceite de maíz.

Los animales, del grupo experimental $y$ sus controles, se sacrificaron en grupos de 5 , a los: $4,8,18,28$ y 40 días postaplicación intraperitoneal, y luego se realizaron las observaciones pertinentes. Dichos intervalos de tiempo se estimaron con ayuda del Programa Stages Ver.1.4.

Proceso de Captación de Información: Luego del sacrificio de los ratones, se procedió a la disección de los testículos, con el fin de extraer las colas de los epidídimos, estas se colocaron en una Placa Petri con $2 \mathrm{ml}$ de solución de $\mathrm{NaCl}$ al $0,9 \%$ durante 24 horas a $4^{\circ} \mathrm{C}$. Las colas de los epidídimos fueron fragmentadas en dichas placas tratando de lograr una suspensión homogénea.

Conteo Espermático: De la suspensión, se tomaron alícuotas que se colocaron en una cámara de Neubauer hemocitométrica, donde se realizó el conteo espermático siguiendo los procedimientos de conteo de glóbulos rojos, calculándose el número de espermatozoides por mililitro de suspensión. Sólo se contaron espermatozoides con cola y los resultados fueron expresados como millones de espermatozoides por mililitro de suspensión (millones de esp./ml).

Morfología Espermática: Para la observación de la morfología de los espermatozoides, se tomaron alícuotas de la suspensión de las colas de los epidídimos; estas se fijaron en formalina neutral, para luego ser extendidas en una lámina portaobjetos, secadas al aire y después coloreadas con hematoxilina-eosina. El examen se realizó con un microscopio óptico, con un aumento de $1000 \mathrm{X}$, siguiendo las técnicas microscópicas tradicionales. Se examinaron 100 espermatozoides por cada muestra, clasificán-

Tabla 1: Efectos del Malathion Sobre la Espermatogénesis de Ratones Machos Jóvenes de la Cepa Balb-C53, Según Conteo de Espermatozoides e Intervalos de Sacrificio Postinyección. FMH-DAC. UNICA. Ica. 2003.

\begin{tabular}{|c|c|c|c|c|}
\hline \multirow{2}{*}{$\begin{array}{l}\text { Intervalos de sacrificio } \\
\text { (días) }\end{array}$} & \multicolumn{2}{|c|}{ Conteo espermático (millones $/ \mathrm{ml}$ ) } & \multirow{2}{*}{$\begin{array}{c}\text { ANOVA } \\
F\end{array}$} & \multirow{2}{*}{$\begin{array}{c}\text { Significación } \\
p\end{array}$} \\
\hline & Experimental & $\begin{array}{c}\text { Control } \\
\text { Media }+\mathrm{DS}\end{array}$ & & \\
\hline 4 & $374,80 \pm 94,25$ & $365,60 \pm 173,45$ & 0,01 & 0,92 \\
\hline 8 & $406,20 \pm 90,36$ & $349,60 \pm 181,19$ & 0,39 & 0,55 \\
\hline 18 & $552,20 \pm 95,16$ & $633,20 \pm 276,00$ & 0,39 & 0,55 \\
\hline 28 & $458,00 \pm 114,34$ & $683,60 \pm 142,67$ & 7,61 & 0,03 \\
\hline 40 & $519,80 \pm 102,72$ & $796,40 \pm 226,91$ & 6,17 & 0,04 \\
\hline
\end{tabular}

dolos según las alteraciones morfológicas observadas, al compararlos con un modelo pre-establecido de normalidad. En este trabajo se consideró como teratozoospermia a cualquier anormalidad de la cola, cabeza o segmento intermedio de un espermatozoide. La cuenta de espermatozoides anormales fue expresada en número de células por 100 espermatozoides observados (\% esp. anormales).

Análisis Estadístico: Una vez recolectada la información de cada uno de los experimentos, en fichas especialmente diseñadas, sin considerar aún su categoría como grupo experimental o control; y teniendo todas las pruebas depuradas, se procedió a la identificación de los resultados de los diferentes ratones como correspondientes a los dos grupos de estudio. Los datos fueron transferidos a una base de datos elaborada el programa SPSS Ver. 10.0 para Windows; con el que fueron procesados y analizados.

El análisis univariado consistió en calcular las medias y desviaciones estándar del conteo espermático y del número de espermatozoides. El análisis bivariado consistió en comparar las medias de las mediciones efectuadas en ambos grupos, para cada intervalo de sacrificio, mediante el modelo matemático ANOVA; cumpliendo los criterios de aleatoriedad, normalidad y homogeneidad de varianzas. En todas las comparaciones se consideró como significativa una $p \leq 0,05$. Para la mejor comprensión de los resultados se elaboraron tablas $y$ figuras que permitieron observar las diferencias de las medias de ambos grupos por periodos de sacrificio.

\section{RESULTADOS}

En este estudio, se encontró que la media del conteo de espermatozoides del epidídimo aumentó con la edad en los dos grupos. El conteo espermático de los ratones tratados con Malathion fue ligeramente mayor a los 4 y 8 días postinyección; en cambio, en los siguientes intervalos de sacrificio éste, fue siempre inferior al del grupo control. Existiendo diferencias significativas, entre ambos grupos, sólo a los 28 y 40 días postexposición intraperitoneal al Malathion ( $E$ : 458,00 y 519,80 millones esp./ml vs C: 683,60 y 796,40 millones esp./ml respectivamente, para un $\mathrm{p} £ 0,05$ ) [Tabla 1].

La media del porcentaje de espermatozoides anormales fue mayor en el grupo experimental en todos los intervalos de sacrificio; sin embargo, las diferencias fueron significativas, sólo a los 4 y 8 días postaplicación intraperitoneal del Malathion (E: 13,60 y $8,40 \%$ de esp. anormales vs C: 4,60 y $2,40 \%$ de esp. anormales respectivamente, para un $\mathrm{p} £ 0,05)$. También se observó, que en ambos grupos, a los 8 y 18 días hubo una caída de la teratozoospermia con recuperación en los posteriores periodos [Tabla 2].

\section{DISCUSIÓN}

Esta investigación estudia el efecto de una sola dosis intraperitoneal, del agropesticida órganofosforado Malathion, sobre la espermatogénesis de ratones machos jóvenes de la cepa Balb-C53 de 30 días de edad. Es necesario indicar que en los ratones, la espermatogénesis comienza después

Tabla 2: Efectos del Malathion Sobre la Espermatogénesis de Ratones Machos Jóvenes de la Cepa Balb-C53, Según Porcentaje de Espermatozoides Anormales e Intervalos de Sacrificio Postinyección. FMH-DAC. UNICA. Ica. 2003.

\begin{tabular}{|c|c|c|c|c|}
\hline \multirow{2}{*}{$\begin{array}{l}\text { Intervalos de sacrificio } \\
\text { (días) }\end{array}$} & \multicolumn{2}{|c|}{$\%$ de espermatozoides anormales } & \multirow{2}{*}{$\begin{array}{c}\text { ANOVA } \\
F \\
\end{array}$} & \multirow{2}{*}{$\begin{array}{c}\text { Significación } \\
p\end{array}$} \\
\hline & $\begin{array}{c}\text { Experimental } \\
\text { Media } \pm \text { DS }\end{array}$ & $\begin{array}{c}\text { Control } \\
\text { Media } \pm \mathrm{DS}\end{array}$ & & \\
\hline 4 & $13,60 \pm 2,97$ & $4,60 \pm 2,30$ & 28,72 & 0,001 \\
\hline 8 & $8,40 \pm 4,34$ & $2,40 \pm 2,51$ & 7,17 & 0,03 \\
\hline 18 & $4,60 \pm 3,97$ & $2,80 \pm 2,77$ & 0,69 & 0,43 \\
\hline 28 & $10,80 \pm 8,35$ & $6,00 \pm 3,54$ & 1,40 & 0,27 \\
\hline 40 & $12,20 \pm 7,66$ & $8,60 \pm 5,22$ & 0,75 & 0,41 \\
\hline
\end{tabular}


del nacimiento y a los 28 días está cualitativamente terminada pero no cuantitativamente completa.

Los resultados del presente estudio sugieren que la administración de Malathion afecta el conteo espermático, al observar un menor número de espermatozoides en el grupo experimental a los 28 y 40 días postinyección intraperitoneal. Similares resultados fueron encontrados por Sobarzo et al. ${ }^{6}$ y Bustos-Obregón ${ }^{1}$, en ratones inmaduros y adultos respectivamente, tratados con Parathion. La disminución del número de espermatozoides en los ratones expuestos a Malathion, podría explicarse por la acción que ejercen los órganofosforados sobre el ADN, ocasionando microdelecciones y mutaciones en genes que controlan la espermatogénesis. Por otro lado, Contreras y Bustos-Obregón ${ }^{5}$ observaron que ratones adultos, expuestos a Malathion, presentaban conteos espermáticos altos asociados a una alta teratozoospermia. Este efecto no se observó en nuestro estudio.

De acuerdo a los resultados, Malathion podría afectar la morfología de los espermatozoides, al observarse un mayor porcentaje de anormalidades espermáticas (teratozoospermia), en el grupo experimental, a los 4 y 8 días postexposición. Otros investigadores ${ }^{1,5,6}$ encuentran similares efectos en ratones púberes y adultos expuestos a Parathion, Malathion y otros pesticidas órganoclorados. Los hallazgos, se podrían explicar por los efectos citotóxicos de los órganofosforados, que interfieren con la diferenciación y proliferación de las células espermatogénicas, produciendo alteración de la morfología espermática. Las evidencias que apoyan esta aseveración, muestran los efectos genotóxicos de los órganofosforados sobre el ADN de los precursores espermáti- $\cos ^{6-15}$, y sus acciones alquilantes sobre el ensamblaje de las proteínas flagelares de los espermatozoides ${ }^{5,6}$.

Las propiedades del Malathion para afectar los parámetros antes descritos, podrían sentar las bases de los efectos gonadotóxicos de los pesticidas órganofosforados sobre la espermatogénesis de ratones jóvenes; sin embargo, es necesario realizar otros estudios a nivel celular y molecular para corroborar estas propiedades.

\section{CONCLUSIÓN}

El Malathion en una sola dosis intraperitoneal, puede afectar la espermatogénesis de ratones jóvenes de la cepa Balb-C53, produciendo disminución del conteo espermático y aumento del número de espermatozoides anormales.

\section{REFERENCIAS BIBLIOGRÁFICAS}

1. Bustos-Obregón E, Valenzuela-Estrada M. Agropesticidas en andrología. Conceptos básicos y modelo animal. Boletín Informativo de la Sociedad Argentina de Andrología 1998; 7:4-10.

2. Roldan ERS, Hernández ER. Descenso de la calidad del semen humano: contaminantes ambientales y microdeleciones del cromosoma Y. Endocrinología 1998; 45:298-302.

3. Sobarzo C, Bustos-Obregón E. Acute effect of parathion on the seminiferous epithelium of immature mice. Rev Chil Anat 2000; 18:45-47.

4. Bustos-Obregón E, Díaz O. Ultrastructure of mouse teratozoospermia induced by Parathion. Asian Journal of Andrology 1999; 1:1-2.

5. Contreras $\mathrm{H}$, Bustos Obregón $\mathrm{E}$. Morphological alterations in mouse testis by a single dose of malathion. Journal Of Experimental Zoology 1999; 284:355-359.

6. Sobarzo C, Bustos-Obregón E. Sperm quality in mice acutely treated with parathion. Asian Journal Of Andrology $2000 ; 2: 147-150$.

7. Contreras H, Badilla J, Bustos-Obregón E. Morphofunctional disturbances of human sperm after incubation with organophosphorate pesticides. Biocell 1999; 23:135-141.

8. Rodríguez $\mathrm{H}$, Bustos-Obregón $\mathrm{E}$. An in vitro model to evaluate the effect of and organophosphoric agropesticide on cell proliferation in mouse seminiferous tubules. Andrología 2000; 32:1-5.

9. II Congreso De Anatomía Del Cono Sur XXI Congreso Chileno De Anatomía XXXVII Congreso Rioplatense De Anatomía. Rev Chil Anat 2001; 19:73-123.

10. Hardman JG, Limbird LE, Molinoff PB, Ruddon RW, Goodman-Gilman A. Editores. Goodman \& Gilman: Las Bases Farmacológicas De La Terapéutica. 9ª Ed.. Madrid: Interamericana Mcgraw-Hill; 1998.

11. Sierra-Torres C, Cajas-Salazar N, Hoyos L, Zuleta M, Whorton E, Au W. In vitro and in vivo genotoxic activity of miral, and organophosphorous insecticide used in Colombia. Mutation Research 1998; 415:59-67.

12. Windham G, Titenko-Holland N, Osorio A, Gettner S, Reinisch F, Haas R, Smith M. Genetic monitoring of malathion-exposed agricultural workers. American Journal Of Industrial Medicine 1998; 33:164-174.

13. Blasiak J, Jaloszynski P, Trzeciak A, Szyfter K. In vitro studies on the genotoxicity of the organophosphorous insecticide malathion and its two analogues. Genetic Toxicology and Enviromental Mutagenesis 1999; 445:275283. 